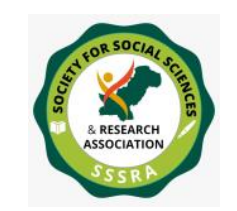

\title{
CPEC: POLITICAL ENVIRONMENT CHANGER FOR CENTRAL ASIAN REPUBLICS
}

\author{
Dr. Suwaibah Qadri \\ Assistant Professor \\ Department of Political Science \\ University of Karachi \\ Karachi - Pakistan \\ suwaibahq@gmail.com
}

\begin{abstract}
States are more inclined to create alliances with one another for economic growth since regional cooperation has the potential to boost small governments. As part of their efforts to shift the political atmosphere, Pakistan and China have taken steps towards improving their regional cooperation through connectivity. The China-Pakistan Economic Corridor (CPEC) is a significant component of China's Belt and Road Initiative (BRI). As a result of the China-Pakistan Economic Corridor (CPEC) and the economies of its neighbours, notably the Central Asian Republics, Pakistan's GDP will develop dramatically. The signing of the agreement between Central Asia and South Asia is another CPEC-related economic initiative, as is CASA-1000 (CASA-1000). The TAPI oil pipeline, which will link Turkmenistan with Afghanistan, Pakistan, and India, will be inaugurated at the same time. It is written from the perspective of Pakistan and the CARs' harmonic basis. The CPEC's value for China, Pakistan, and other nations as well as CARs is also examined.
\end{abstract}

Keywords: Pakistan, China, CPEC, Economic Growth, Connectivity.

\section{Introduction}

In order to deal with the problems that impede economic growth and put national security at risk, effective solutions lie in regional collaboration and peaceful cohabitation between nations. The idea of regional cooperation has gained traction as a means of bringing governments closer together in order to meet new problems. Building a region is the primary goal of regionalism, which focuses on determining the growth of the region and addressing the shared challenges. With the goal of fostering more regional collaboration and creating a less volatile region, the notion of regionalism has been put forth. It is 


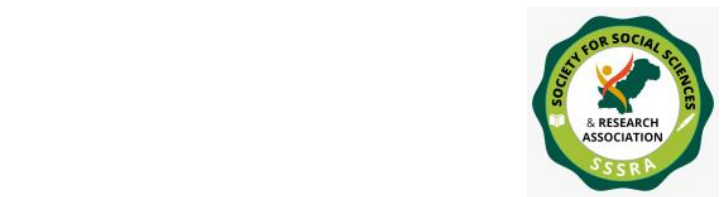

Pak. Journal of Int'L Affairs, Vol 4, Issue 3 (2021)

CPEC: Political Environment Changer for ...

currently taking shape as South Asia looks for energy-producing states and Central Asia is a hub of energy-rich states ready to export their natural resources. This region is based on economic and cultural affinities, the potential for interdependence between Central and South Asian states and their shared geopolitical importance. In the past, great nations have attempted to integrate Central Asia through collaboration and regional cooperation, but these efforts have been unsuccessful (Delovarova, 2013). Central Asia's geography suggests that it may serve as a transportation centre. Because of its proximity to China, Western Asia, and South Asia, it is an ideal crossroads for East and West (Javed, 2015). Since the economies of the countries in Central and South Asia are so disparate, regionalization appears to have an unbalanced nature. This has all changed because to China's BRI, which is working on the CPEC in partnership with Pakistan. Numerous projects are now in development to meet the demands of transformation, with CPEC serving as the pilot project for the BRI. However, the projects' progress is being slowed by shifting regional dynamics. India's increasing efforts to link up with Afghanistan and undermine CPEC and other initiatives of connection with CARs have reached their apex, and this poses the greatest threat.

Terrorism against Pakistan from Afghanistan is another reason delaying down connection initiatives. This raises a question: How can Central Asian countries (CAR) access Gwadar Port if Pakistan and Afghanistan are still feuding over the latter's nuclear programme? The purpose of this research is to assess the impact that CPEC has had on the political climate along the route that connects Pakistan with the CARs in Central Asia. CARs' trade relations with Pakistan and other countries would be strengthened thanks to CPEC, as the report points out. A number of distinct aspects of CPEC's usefulness are also examined in the research. First, the case is examined via a geographic lens, and then economic elements and future possibilities are examined.. Finally, some advice is offered. While CPEC is driving regional development, various initiatives of connectivity are being examined in order to study South Asia's connection to Central Asia.

\section{Chinese and Central Asian Interdependence}

The cultural connection between the CARs and Xinjiang is a crucial component in China's relationship with the CARs. Central Asian (Turkish speaking) people that live in Xinjiang, a Chinese province, have a long history of trading with each other (Panda, 2006). Furthermore, China's internal policy is focused on economic ties with Central Asia and the help of its neighbours in securing its borders (Lain, 2016). Chinese finance and construction of transportation routes will bring the CARs within Beijing's strategic circle. There are six corridors altogether in China's BRI, which include the Eurasian Land 


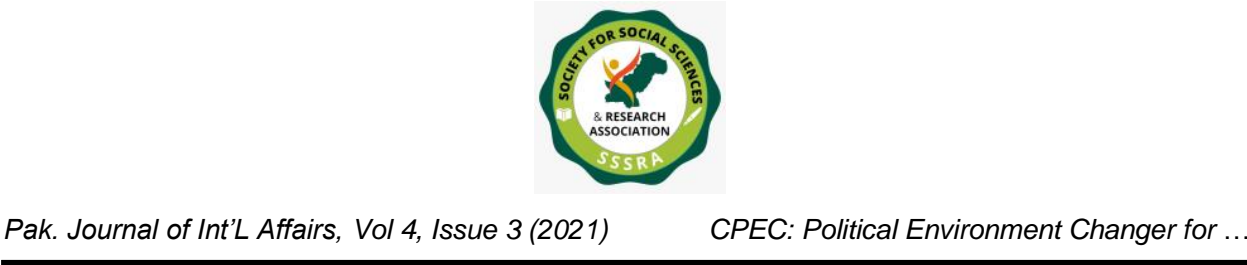

Bridge, China-Central and West Asia Corridor, Maritime Silk Road (Indochina Peninsula), China-Russia Corridor, and the BCIM Corridor (The Belt and Road Initiative, 2018). In contrast to the other corridors, which connect at least three nations, only the CPEC is a two-party enterprise. To begin with, the ancient Chinese Silk Road links with Central Asia, and eventually the rest of the world (Malik, 2017).

Despite China's efforts to connect Gwadar and Kashgar, it also satisfies the standards of CARs in the process. As a result of this move, Central Asia and Pakistan may finally be able to establish diplomatic relations after decades of estrangement. As a result, China has a long-standing partnership with CARs, as well as oil and gas transportation and commerce for a wide range of products. The port of Gwadar and the roads that connect it are like the Suez Canal in that they reduce long trade routes and benefit all parties involved in the transaction. In 1996, China and Russia gave CARs a venue, the Shanghai Five, to discuss their concerns. Pakistan also indicated an interest in joining the Shanghai Cooperation Organization (SCO), which was later renamed the SCO. After China's president visited Pakistan in 2017 and formally opened the CPEC project, Pakistan became a member of the SCO. The fact that both Pakistan and India are now members of the SCO is further proof that geographical ties are forming between countries in South Asia and those in the Caribbean. Russia and China, both rising nations whose development is based on cooperation, are now linked by regional integration initiatives. However, this is just the beginning of a regional alliance that might one day take over Eurasia (Cronin, 2009).

\section{Paralysis of Geography}

Tajikistan is the closest Central Asian nation to Pakistan's borders, and the region is known as Central Asia. Pakistan and Central Asia have a strong link, despite the fact that they don't share a boundary. Terrorism and drug trafficking are two of the issues the Central Asian Republics and Pakistan are now working together on. In 1991, Pakistan dispatched a delegation to the CARs, which comprised businessmen and government officials, and signed various memoranda of understanding. Both the TAPI gas pipeline project and the CASA-1000 (Central Asia-South Asia Electricity Transmission Project) signed by Pakistan, Afghanistan and the Central Asian Republics are key projects in the energy industry.

The fact that the CARs are landlocked nations is one of the issues preventing them from reaching a significant economic takeoff. They are unable to trade or travel by sea because they lack access to warm seas. In contrast to states that have direct access to the ocean, they tend to have lower per capita income. Central Asian countries have been trying for 


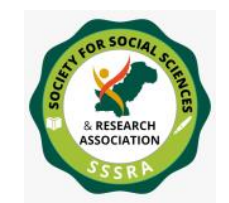

decades to gain access to regional markets, particularly those of India, China, West Asia and Pakistan. Additionally, they are attempting to expand their markets to the West via the Indian Ocean. As a result, the CPEC will give the landlocked CARs a way to expand their trade ties with the rest of the world, and Gwadar Port will serve as that gateway. All parties will benefit from greater social integration and regional economic as a result of the CPEC. As a result, the region is expected to attract foreign direct investment (FDI) and industries from other economic heavyweights. Since the Central Asian nations are wealthy in natural resources, particularly vast energy reserves, Pakistan and China have a considerable interest in the region. To prevent conflict and increase regional connectedness and regional integration, bilateral and international commerce and interdependence is probable. However, it's not all plain sailing for the nations who are interested in such projects as Pakistan and China are planning under the CPEC. Because the United States and India may not want it to succeed, they may see it as a danger to their strategic goals. This helps to explain why Washington and New Dehli have developed a developing strategic partnership. As Pakistan's longtime adversary, India is seeking to undermine the project by disrupting its border with Pakistan and reportedly intervening in Pakistan's domestic affairs. However, the CPEC is under urgent threat from the west, not the east, of Pakistan.

\section{The Afghanistan Dilemma}

Afghanistan's neighbours and the rest of the region depend on the country's capacity to maintain peace and stability. For more than a decade now, Afghanistan has been in a perpetual state of flux following the American invasion following the 9/11 terrorist attacks. Since taking control of Afghanistan in 2001, the Taliban has been a prominent player in the peace process. Pakistan has also been affected by the ongoing conflict. Because of this, a stable and secure Afghanistan is in the best interests of all regional countries. China has also been working on this issue through the Quadrilateral and Shanghai Cooperation Organization conferences, as well as through significant investments in Afghanistan. Although the China-Pakistan Economic Corridor (CPEC) route from Afghanistan to Pakistan looks to be the shortest path for China to connect itself to the Indian Ocean, Pakistan has alternative options (for example, it can use its route through Kashghar for commerce with CARs). As a result, Afghanistan's stability and security are critical to the success of the CPEC. In terms of speed and effectiveness, Afghanistan is the most direct and efficient connection connecting Central Asia and China and Pakistan. By going via Afghanistan in their commerce with one another, the CARs, Pakistan, and China may be able to save both time and money. Despite its strategic relevance to regional connectivity, Afghanistan's security difficulties and internal political dynamics have been a major impediment to the process. 


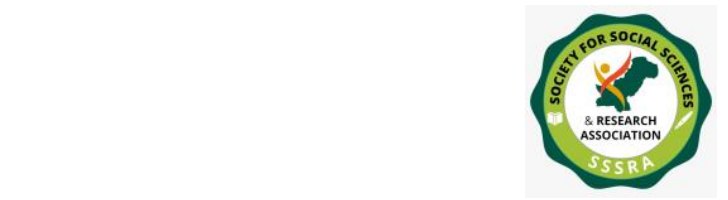

CPEC: Political Environment Changer for ...

Since NATO soldiers began withdrawing from Afghanistan, there have been a number of violent incidents and attacks. In addition to peace, Afghanistan needs stability, and this may be achieved through trade and development. There are no development initiatives taking place in Afghanistan, despite the country's abundance of natural resources. For the year 2015, Afghanistan shipped 72 percent of its total export commodities to Pakistan and India, which included carpets, dried fruit and medicinal plants. In addition to copper and iron ores, Afghanistan has a wealth of other important minerals, although they are seldom exported due of the country's lack of access to these resources. A 30-year deal was reached in 2008 between the Chinese government and the Afghan government for the exploration of the MesAynak copper deposit, the second biggest in the world. Because of Taliban strikes and other security concerns, the $\$ 3$ billion deal was put on hold. As a result of the country's security concerns, many investors have decided to avoid making any investments in Afghanistan.

China is well aware of Afghanistan's strategic relevance to the CPEC and has increased security cooperation by providing more aid to the nation. China. Afghanistan's peace talks with the Taliban have been facilitated in large part by China. Because of this, the CPEC, as well as China's western area, including the autonomous province of Xinjiang, are at risk from Afghanistan's instability. Afghanistan's inclusion into the regional economy will be aided by security and stability in this setting. Foreign direct investment (FDI) might provide long-term wealth to Afghanistan if the country becomes more stable and safe. The present security situation in Afghanistan necessitates the adoption of other routes to connect Central Asia to Pakistan's Gwadar Port. China's westernmost province, Xinjiang, provides Pakistan with an alternative route to Central Asia. Even if a road network can be built along this line, the cost and time required to do so, as well as the possibility for Uighur terrorism, make this route a dangerous investment at the moment. In spite of this, the road network is adequate. As a result, China appears to be Pakistan's backup choice for connecting the country's south with Central Asian countries. As long as Afghanistan remains unstable, products can be transported via the Pakistan-ChinaCentral Asia corridor. Afghanistan cannot be bypassed when it comes to the transportation of energy, such as gas pipelines.

\section{Pakistan's Role in CAR Integration}

As a result of their shared history, religion, and culture, Pakistan and the Central African Republic (CAR) have developed a strong political and diplomatic relationship. The CARs look to be preparing to expand trade and to minimise their dependency on Russia for energy exports, and they are also striving to lessen their reliance on Russia alone (Hyder, 2011). They appear to be expanding their policy to include the southern and western 


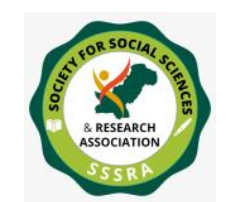

Pak. Journal of Int'L Affairs, Vol 4, Issue 3 (2021)

CPEC: Political Environment Changer for ...

states. These qualities, together with a strong cultural affinity between the two countries, make Pakistan a viable option for CARs to link to. As early as 1991, Pakistan recognised CARs and hoped to build economic links with them, but despite their best efforts, commercial relations failed to take off. When it came to trade with Pakistan, the insecurity in Afghanistan had been a major impediment. Pakistan and Central Asia's economic troubles have been alleviated by the creation of the CPEC. Shipments to regional markets will be easier for CARs because Pakistan has a direct link between South Asia and the Gulf region (Shahbazov, 2017). When Pakistan opened Karachi and Bin Qasim ports for the first time in the 1990s, they were overloaded. For the building of Gwadar Port, China donated Pakistan 248 million dollars in 2001. After the Singapore Port Authority (PSA) took over operation of the port in 2007, it was unable to prosper. in 2013 CPHC was granted management rights to the port, and the requisite infrastructure was built (Raza, 2013). The port was operational in November 2016, and road building is now underway. The money allocated, which was earlier 46 billion dollars, has now climbed to 62 billion dollars due to the introduction of new projects (Siddiqui, 2017).

As a result of the initiative, trade networks in South and Central Asia stand to benefit greatly. In addition to China's investment in Gwadar port, the energy-rich CARs have enormous commercial opportunities because of Gwadar's ability to provide its oil and gas. Gas pipelines worth billions of dollars might be stored at Gwadar, should all go according to plan (Ruff, 2016). As a result, it is expected that CPEC would create new economic prospects for Central Asia. "Pakistan may be a bridge between energy-rich Central Asia and Iran on one side and energy-deficient nations like China and India on the other," said Sartaj Aziz, Pakistan's former Adviser to the Prime Minister on Foreign Affairs (Aziz, 2016). In light of this, Central Asian countries have reacted favourably to Pakistan's role as the corridor's only direct trade route. Thus, despite Afghanistan's incompetent efforts to stifle connectivity projects in the region, the countries of Kyrgyzstan, Tajikistan, and Turkmenistan have agreed to supply Pakistan with energy, gas, and oil. This speaks volumes about the attitudes of CARs toward Pakistan and the significance of CPEC in their eyes. The three countries bordering Afghanistan (Turkmenistan, Uzbekistan, and Tajikistan) plan to strengthen business ties and participate in a variety of energy initiatives. There is now a limited energy linkage between Afghanistan and Central Asian power producers. Having stable neighbours and growing economic activity is, of course, a good sign for the future. South and Central Asia are bolstered by the CARs' vast natural riches and Pakistan's key position. The fact that CARs are looking for a way into global markets through the port of Gwadar and that Pakistan has a significant geopolitical role in regional connectivity and stability is wellestablished. CARs are well-positioned to invest in CPEC's industrial zones, which are rich in natural resources like as gold, oil, gas, and other metals. In light of the enormous 


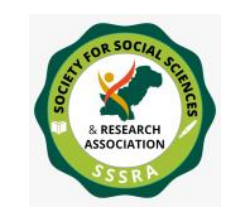

Pak. Journal of Int'L Affairs, Vol 4, Issue 3 (2021)

CPEC: Political Environment Changer for ...

potential for commerce and transportation, as well as investment, practically all of the CARs have shown an interest in participating in the CPEC. As a result of China's influence on these countries, the two areas are being drawn closer together.

\section{Regional Connectivity Projects}

All three of these elements are intertwined in the Central Asia-Pacific Economic Cooperation (CPEC). CPEC's ripple effect is clearly obvious since South Asian economies are growing rapidly, resulting in an increase in energy consumption. There are a number of new energy projects (seemingly unrelated to each other), including the signing of South Asia-Central Asia (CASA 1000) and the launching of the TAPI gas pipeline, which signal a move from rivalry to cooperation in the region. States, despite their differences of opinion, are eager to join forces and form economic and political relations, despite their differences of opinion. Geographic closeness appears to be a major tying factor in this case. However, the execution of regional connection projects has a number of hiccups. Afghanistan, for example, has demanded that if it joins CPEC, a transit route known as Wagha be granted to it, connecting India to Pakistan (President Ghani, 2017).

CARs are landlocked, preventing economic growth, and their security issues are extremely customised (Tanrisever, 2013). Economic growth, regional peace, and connectivity are the goals of Pakistan and China, as well as the Central Asian Republics (CARs). CASA-1000 and TAPI pipeline projects, which are different from the CPEC, show that the CARs and Pakistan share mutual interests. These projects might be referred to as BRI and CPEC "spillovers." The CASA-1000 seeks to build the Central Asia-South Asia Regional Electricity Market in order to relieve South Asia's energy crisis (CASAREM). Tajikistan to Pakistan via Afghanistan would include a $750 \mathrm{~km}$ high voltage direct current (DC) transmission link with the construction of converter stations at Sangtuda (1,300MW), Kabul (300MW), and Peshawar (1,300MW)." In 2015, (Kiani, 2015). A fibre optic connection of 820 kilometres connecting Khunjrab with Rawalpindi is also being built, which will connect Havelian and Kashgar through a railway track. As a result, three industrial zones have been designated so far: Hattar, Faisalabad, and Dhabeji (Malik, 2017). The CASA-1000 electrical transmission project and TAPI gas pipeline project are genuinely targeted at bringing energy from Central Asian republics, Tajikistan and Kyrgyzstan, through Afghanistan and ultimately to Pakistan. After four months of TAPI's inauguration, Tajikistan staged the ground-breaking of CASA 1000 in Dushanbe, Tajikistan, which is remarkable. Both initiatives are expected to cost between $\$ 1$ billion and $\$ 4$ billion. They can, however, transport 1,000 MW of power and 33 billion cubic metres of gas each year to Pakistan. As a result of this, Afghanistan will be 


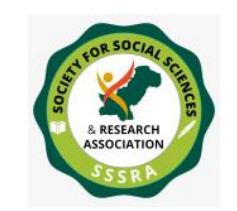

CPEC: Political Environment Changer for ...

able to serve as a hub between the two developing economic regions and emerge from its current state of political and economic instability (Mudabber, 2016). For nations like Tajikistan and Turkmenistan, trade gains would be substantial while increasing energy supplies in Afghanistan/Pakistan and India significantly. Projects like this one might have a positive impact on energy exchange between Central Asia and South Asia. For Afghanistan's economic growth, the fact that 75 percent of the pipeline runs through Afghanistan is intriguing.

TAPI's regional connection is strong, allowing nations in South Asia with energy deficits to receive natural gas. The United States formerly supported this project because it aimed to provide South Asia with Central Asian Gas on its own. In addition, TAPI will bypass Iran and transport gas to Pakistan and India via Afghanistan. This has changed, and Turkmenistan is ready to export its mineral and energy resources to profitable markets. At this point in time, security concerns are widespread in the early stages of CPEC and TAPI, mainly due to Afghanistan's ongoing insecurity. According to CAREC, the TransAsian Pipeline Initiative (TAPI) is a critical link in the region's energy grid (Strategy for Regional Cooperation in the Energy Sector of CAREC Countries, 2008). First and foremost, the TAPI and CAREC's goals aim to achieve energy security through the development of regional institutions and infrastructure. Three, an improvement in economic growth as a result of enhanced energy trade (Mudabber, 2016). The path of the TAPI, which begins in Turkmenistan's Dauletabad gas field and ends in Pakistan's Bolan Pass, reveals its geographical features and importance (Baluchistan). After then, it will cross the Fazilka-Pakistan border in India (Kar, 2016). The security of these projects has been the primary worry of all stakeholders since NATO's departure.

Therefore, authorities in certain states that are unwilling to bend must understand that the CPEC route offers enormous prospects for CARs as well as everyone else connected to it. For Afghanistan, the project would bring in profits and provide cheap power. State-tostate collaboration is developing because of Pakistan's attempts to boost cooperation with CARs. As a result of their economies centred on primary products, CARs are looking for partners that can assist them in shipping their goods to large markets. CARs need to interact with the global economy in order to prosper economically. South Asian and Central Asian countries share a number of commonalities, such as their proximity to one another, the Muslim Brotherhood, and a growing interdependence in the energy industry. There are several benefits to implementing the projects outlined above, including increased economic activity and a reduction in hostilities between states. South and Central Asia would be linked through Afghanistan as a major transit point. As a result, the success of Afghanistan's connection initiatives depends on the country's security condition. It is clear that peace in Afghanistan has become the primary objective of all 


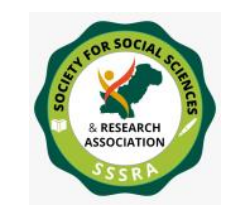

Pak. Journal of Int'L Affairs, Vol 4, Issue 3 (2021)

CPEC: Political Environment Changer for ...

players. Economic expansion may lead to new ideas and a reduction in the violent attitude if individuals were involved in enterprises.

\section{Recommendations}

The security situation in Afghanistan has been tense for years, and all Pakistan-CAR connection initiatives are dependent on it. As a result, Afghanistan's Pacific surroundings are needed to initiate development initiatives, economic advancement, and links between South and Central Asia. Pakistan, China, and the Central Asian Republics (CARs) all want to establish peace and security.

- The media (in Afghanistan, Pakistan and CARs) must aggressively promote the port's commerce and connectivity advantages for CARs.

- Signing new deals with Turkmenistan, Tajikistan and Uzbekistan would help improve relations between Pakistan and Afghanistan.

- Tajikistan, Kazakhstan and Kyrgyzstan should be urged to adopt an alternate route through China (bordering China) to connect with CPEC instead of joining CARs through the Kabul or Wahkhan corridor.

- Cargo service between the CARs and Pakistan should be rapid in order to stimulate trade.

- The project's success depends on the collaboration of the federal government, institutional performance, and popular support.

- Turkmenistan and Uzbekistan should also be encouraged to continue utilising land from other nations in order to speed up economic endeavours. As a result, connectivity will be more certain, and relationships will improve.

\section{Conclusion}

Future dependency is likely to be a result of CPEC as well. As a natural link between the members of CPEC, TAPI, SCO and CASA-1000, Pakistan is an ideal place for Pakistan to be. With China's strong ties to Kyrgyzstan, Tajikistan and Pakistan, the country's position is vital to these initiatives. All connection initiatives in South and Central Asia now revolve through Pakistan thanks to the recent expansion of the SCO, which demonstrates regional collaboration. Khunjrab to Gwadar would become a viable link between China and Central Asia and the rest of the globe if the infrastructure was completed. Central Asian countries are interested in using Gwadar port in order to gain access to the sea. Trade routes may hinder the favourable effects of connectivity initiatives on CARs until they are operational in Afghanistan. As a means of ensuring regional peace, China invests in neighbouring nations' growth, as well as creating 
infrastructure. The Chinese government thinks that economic growth is the best way to alleviate poverty and ensure peace and security. Its goal is to provide economic prosperity to the region by connecting South Asia and Central Asia. For all intents and purposes, CPEC was built with the goal of peaceful coexistence, not competition. As a result, CPEC has boosted the appeal of all connectivity projects, even those that appear to be unrelated. Infrastructural development will play a key role in ensuring regional stability as the area continues to integrate. 
CPEC: Political Environment Changer for ...

\section{References}

Aziz, M. S. (2016, June 9). Ministry of Foreign Affairs. Retrieved from http://www.mofa.gov.pk/pr-details.php?mm=Mzg0NA,,.

Cronin, P. M. (2009). Global Strategic Assessment 2009: America's Security Role in a Changing World, 256.

Delovarova, A. D. (2013). Regionalism and Regionalization in Central Asia. World Academy of Science, Engineering and Technology, International Journal of Humanities and Social Sciences, 7(3), 778-781.

Hyder, T., O., (2011, September 14) "Central Asia, Making up for Lost Time" The Express Tribune.

Javed, U., A. R. (2015). Oil and Gas Potentials of Central Asian Republics and. South Asian Studies, 30(1), 127-148.

Kiani, K., (2015, April 27). Casa-1000 breakthrough, Dawn

Lain, J. K. (2016, April 27). China's Silk Road in Central Asia: Transformative or Exploitative? Retrieved from Financial Times: https://www.ft.com/content/55ca031d3fe3-3555-a878-3bcfa9fd6a98

Malik, A. R. (2017, November 21). CPEC: Relevance to Central Asia. The Nation, Islamabad.

Malik, A. R. (2017, November 21). CPEC: Relevance to Central Asia. The Nation, Islamabad.

Manish, V. \& Sanjay, K.(2016, February) "TAPI Pipeline Progresses but future Uncertain", Oil and Gas Journal, www.ogj.com/articles/print/volume114/issue5/transportation/tapi-pipeline-progresses-but-future-uncertain.html

Mudabber, Z. (2016, July 12). Afghanistan's Role in the Central Asia-South Asia Energy Projects. The Diplomat. https://thediplomat.com/2016/07/afghanistans-role-inthecentral-asia-south-asia-energy-projects/ 
CPEC: Political Environment Changer for ...

Mudabber, Z. (2016, July 12). Afghanistan's Role in the Central Asia-South Asia Energy Projects. The Diplomat. https://thediplomat.com/2016/07/afghanistans-role-inthecentral-asia-south-asia-energy-projects/

President G., (2017, October 25). No to CPEC unless Pakistan provides trade access to India: Dawn.

Raza, S. I. (2013, February 18). China given Contract to Operate Gwadar Port. Dawn.

Siddiqui, S. (2017, August 12). CPEC investment pushed from $\$ 55 \mathrm{~b}$ to $\$ 62 \mathrm{~b}$. The Express Tribune.

Ruff, A., (2016, May 25) "Pakistan seeks stronger ties with Central Asia", Asian Tribune, http://www.asiantribune.com/node/87035.

Shahbazov, F. (2017, May 25). Will the China-Pakistan Economic Corridor Be a Gateway to Central Asia? The Diplomat.

Strategy for Regional Cooperation in the Energy Sector of CAREC Countries. (2008, November 19-21). Central Asia Regional Economic Forum. BAKU, Azerbaijan, 16.

Tanrisever, O. F. ed., (2013) Afghanistan and Central Asia: NATO's Role in Regional Security Since 9/11, Netherlands: IOS Press.

The Belt and Road Initiative. (2018, May 3). Retrieved from HKTDC Research: http://china-trade-research.hktdc.com/business-news/article/The-Belt-andRoadInitiative/The-Belt-and-RoadInitiative/obor/en/1/1X000000/1X0A36B7.htm 